\title{
European Multicenter Study for the Evaluation of a Dual-Layer Flow-Diverting Stent for Treatment of Wide-Neck Intracranial Aneurysms: The European Flow-Redirection Intraluminal Device Study
}

\author{
(D) M. Killer-Oberpfalzer, (D) N. Kocer, DC.J. Griessenauer, (D) H. Janssen, (D)T. Engelhorn, (D) M. Holtmannspötter, (D).H. Buhk, DT. Finkenzeller,
} (D) G. Fesl, (D). Trenkler, (D). Reith, (D) A. Berlis, (D). Hausegger, (D) M. Augustin, (D) C. Islak, DB. Minnich, and (D) Möhlenbruch

\begin{abstract}
BACKGROUND AND PURPOSE: Endoluminal reconstruction with flow-diverting stents represents a widely accepted technique for the treatment of complex intracranial aneurysms. This European registry study analyzed the initial experience of 15 neurovascular centers with the Flow-Redirection Intraluminal Device (FRED) system.
\end{abstract}

MATERIALS AND METHODS: Consecutive patients with intracranial aneurysms treated with the FRED between February 2012 and March 2015 were retrospectively reviewed. Complications and adverse events, transient and permanent morbidity, mortality, and occlusion rates were evaluated.

RESULTS: During the defined study period, 579 aneurysms in 531 patients (median age, 54 years; range, $13-86$ years) were treated with the FRED. Seven percent of patients were treated in the acute phase ( $\leq 3$ days) of aneurysm rupture. The median aneurysm size was $7.6 \mathrm{~mm}$ (range, 1-36.6 mm), and the median neck size $4.5 \mathrm{~mm}$ (range, 1-30 mm). Angiographic follow-up of $>3$ months was available for 516 ( $89.1 \%$ ) aneurysms. There was progressive occlusion witnessed with time, with complete occlusion in 18 (20\%) aneurysms followed for up to $90 \pm$ 14 days, 141 (82.5\%) for $180 \pm 20$ days, 116 (91.3\%) for 1 year \pm 24 days, and 122 (95.3\%) aneurysms followed for $>1$ year. Transient and permanent morbidity occurred in $3.2 \%$ and $0.8 \%$ of procedures, respectively. The overall mortality rate was $1.5 \%$.

CONCLUSIONS: This retrospective study in real-world patients demonstrated the safety and efficacy of the FRED for the treatment of intracranial aneurysms. In most cases, treatment with a single FRED resulted in complete angiographic occlusion at 1 year.

ABBREVIATIONS: ASPIRe = Aneurysm Study of Pipeline in an Observational Registry; EuFRED = European Flow-Redirection Intraluminal Device Study; FRED $=$ Flow-Redirection Intraluminal Device; PUFS = Pipeline for Uncoilable or Failed Aneurysms Study

$F$ ow diversion has become a widely accepted treatment option for all kinds of intracranial aneurysms, especially those with a wide neck. ${ }^{1}$ High rates of complete aneurysm occlusion have been reported in a number of studies, even for large and giant aneu-

Received October 17, 2017; accepted after revision January 12, 2018.

From the Research Institute of Neurointervention/Department of Neurology (M.K.-O., C.J.G.), Paracelsus Medical University, Salzburg, Austria; Department of Neuroradiology (N.K., C.I.), Cerrahpasa Medical School, Istanbul University, Turkey; Department of Neurosurgery (C.J.G.), Geisinger Health, Danville, Pennsylvania; Institute of Radiology and Neuroradiology (H.J., T.F.), Klinikum Nuernberg Sued, Paracelsus Medical University, Nuernberg, Germany; Department of Neuroradiology (T.E.), University Hospital, Erlangen, Germany; Department of Diagnostic Radiology (M.H.), Rigshospitalet, Copenhagen, Denmark; Department of Neuroradiology (J.H.B.), University Hospital Hamburg, Eppendorf, Germany; Department of Neuroradiology (G.F.), Klinikum Grosshadern, University of Munich, Munich, Germany; Department of Neuroradiology (J.T.), Kepler Universitätsklinikum, Linz, Austria; Klinik für Diagnostische und Interventionelle Neuroradiologie (W.R.), Universitätsklinikum des Saarlandes, Homburg/Saar, Germany; Klinik für Diagnostische Radiologie und Neuroradiologie (A.B.), Klinikum Augsburg, Augsburg, Germany; Department of Diagnostic and Interventional Radiology (K.H.), Klinikum Klagenfurt Klagenfurt, Austria; Department of Radiology (M.A.), University Hospital, Graz, Austria; Department of Cell Biology and Physiology (B.M.), Universität Salzburg, Salzburg, Austria; and Department of Neuroradiology (M.M.), Universitätsklinikum Heidelberg, Heidelberg, Germany.

M. Killer-Oberpfalzer and N. Kocer contributed equally to this work. rysms. ${ }^{2}$ Since the inception of the flow-diversion concept, a number of different flow diverters with variations in stent design have been developed and received Conformité Européene or/and FDA approval. Large multicenter cohort studies using 1 of those flow diverters, the Flow-Redirection Endoluminal Device (FRED; MicroVention, Tustin, California), are currently lacking. The device has a paired, integrated dual-layer self-expanding nitinol braided design with an inner low-porosity stent that acts as the flow diverter and an outer part that serves as a scaffold for the inner stent. This dual-layer design is unique among currently available flow-diverting stents. The Pivotal Study of the FRED Stent System in the Treatment of Intracranial Aneurysms ${ }^{3}$ is a current trial in the United States with results expected to be pub-

Please address correspondence to Monika Killer-Oberpfalzer, MD, Research Institute of Neurointervention/Department of Neurology, University Hospital Salzburg, Paracelsus Medical University, Salzburg, Austria, Ignaz Harrerstr 79, 5020 Salzburg, Austria; e-mail: m.killer@salk.at

- Indicates open access to non-subscribers at www.ajnr.org

三 Indicates article with supplemental on-line table.

http://dx.doi.org/10.3174/ajnr.A5592 
lished in 2018. Here, we report the results of the European FRED study (EuFRED), which included 15 European neurovascular centers and evaluated the safety and efficacy of this device in consecutive real-world patients with intracranial aneurysms treated with the FRED.

\section{MATERIALS AND METHODS Statement of Ethics}

Local ethics committees acknowledged this study and the correct use of the patient data. All patients signed consent forms approved by the institutional review boards or the ethics committees.

\section{Study Design}

The EuFRED was a retrospective, multicenter postmarket registry of consecutive patients with intracranial aneurysms treated with the FRED between February 2012 and March 2015 at 15 European high-volume neurovascular centers with experienced neurointerventionalists. Centers had to commit to contribute at least 5 , preferentially consecutive, cases. The decision to use the FRED was at the discretion of the treating neurointerventionalist to reflect application to real-world patients. Patients were eligible for enrollment in the study under the following conditions: 1) They consented to be treated with the FRED flow-diverting device; 2) they met the requirements for FRED treatment per the instructions for use approved for the country in which the patients were treated; and 3) the center agreed to collect data of all consecutive patients. The principal investigator (M.K.-O.) and a steering committee (C.J.G., B.M.) supervised the study design and operations. This study was not funded by an industrial or governmental source. Some of the patients in the present retrospective dataset were included in previously published singlecenter case series. $^{4-6}$

\section{Data Collection}

All centers used the same preprinted data-collection sheets, which specified the data to be collected, study end points, and events of interest. An independent study nurse collected all raw data, and an independent statistician performed statistical analysis. Both were not involved in clinical decision-making. The baseline information studied included demographics, medical history, and aneurysm characteristics. The treatment characteristics collected included the number and size of FREDs and parent vessels, concomitant coil embolization, procedure duration, and use of balloon angioplasty. Clinical and imaging follow-up time points were at the discretion of the center. The clinical condition of patients was recorded according to the modified Rankin Scale score. Follow-up intervals were defined as follows: 1) baseline (before interventional treatment), 2) posttreatment (immediately after the procedure), 3) minimum follow-up (90 days), 4) short-term follow-up (90-180 days after the procedure), 5) midterm follow-up (180-365 days after the procedure), and 6) long-term follow-up ( $>1$ year). Vascular imaging was evaluated in the treating center by an independent neuroradiologist who was not involved in the procedure. Digital subtraction angiography or conebeam CT or both with intravenous contrast administration was performed by 1 year. The technique for subsequent neurovas- cular imaging was at the discretion of the individual center. Aneurysm occlusion grade, in-stent stenosis, and device migration were assessed. Aneurysm occlusion was assessed using a 3-point Raymond-Roy scale and the O'Kelly-Marotta grading scale. ${ }^{7}$ In-stent stenosis was calculated on the basis of the minimal luminal diameter and graded as mild $(<50 \%)$, moderate $(>50$ to $<75 \%$ ), or severe $(>75 \%)$. Device migration was defined as the movement of the device $\geq 5 \mathrm{~mm}$ from its originally deployed location.

All complications and adverse events from the time of treatment to last follow-up were registered. The following complications were specifically collected on the data sheets: 1) spontaneous rupture of the FRED-treated aneurysm, 2) spontaneous nonaneurysmal intracranial hemorrhage ipsilateral or contralateral to the treated aneurysm, 3) symptomatic ischemic stroke, 4) stent/ parent artery stenosis, 5) stent/parent artery occlusion, 6) permanent cranial neuropathy, and 7) other complications that had to be described. Neurologic symptoms due to a stroke were defined as minor if the symptoms resolved within 1 month and major if the patient experienced a clinical deficit for $>1$ month. An adverse event was defined as any procedure-related event that resulted in unexpected difficulties without any decline of the patient's baseline neurologic status. Overall morbidity was defined as transient if the clinical sequelae of the complication resolved within 90 days and otherwise as permanent. Mortality was also recorded.

\section{Flow-Redirection Endoluminal Device}

The FRED is a flow-diverter stent that was released for clinical use in 2012. It has a paired, integrated dual-layer (stent-within-astent) self-expanding nitinol braided design. The inner part of 48 braided nitinol wires determines the working length. It is a lowporosity stent and acts as the active flow-diverting segment at the neck region of the aneurysm, particularly at the inflow zone. The outer part, which determines the total length, is a high-porosity stent with 16 wires, serving as a scaffold for the inner stent. The outer stent is $3 \mathrm{~mm}$ longer than the inner flow-diverter mesh at each end so that these proximal and distal parts of the FRED can be used to cover the adjacent perforating arteries or side branches of the parent vessel.

\section{Technique}

All elective patients were pretreated with dual-antiplatelet medication or, in acute cases, individually according to the practices of the hospitals. All patients were treated under general anesthesia and followed for 24 hours after the procedure in an intensive care unit. Procedures were performed through a $6 \mathrm{~F}-8 \mathrm{~F}$ femoral artery access. A guiding-catheter system was placed into the distal cervical segment of the vessel leading to the intracranial vessel targeted for treatment. A standard 0.027-inch ID microcatheter was then manipulated over a 0.014 - to 0.018 -inch outer diameter microwire into position across the aneurysm neck. When coiling was to be performed in conjunction with FRED treatment, a standard microcatheter was navigated into the aneurysm alongside the 0.027 -inch microcatheter within the parent artery in a jailing technique. Once the 0.027 -inch microcatheter was positioned distal to the aneurysm, the FRED was loaded via a rotating hemo- 
static valve into the hub of the microcatheter and advanced with the delivery wire. The device was then deployed across the targeted landing zone through a process of microcatheter unsheathing and delivery-wire stabilization/advancement. After delivery of approximately two-thirds of the stent length, stent placement was assessed and, if necessary, the stent was resheathed and released again. Once deployed, if coil embolization was to be performed, coils were deployed within the aneurysm through the jailed microcatheter. Following coil embolization, the coiling microcatheter was gently removed from the aneurysm without displacing the construct. Digital subtraction angiography was performed to assess stent placement and the aneurysm occlusion rate immediately after the procedure. Patients continued antiplatelet therapy according to the standard of care in the respective hospital.

\section{Statistical Analysis}

All statistical analyses were performed using SigmaPlot 13 (Systat Software, San Jose, California). Data analysis was based on the patient level, except for aneurysm and procedure characteristics, which were based on the number of aneurysms and procedures, respectively. Values are expressed as percentages. Numbers in parentheses are given for better understanding if indicated. Descriptive statistics were used to present the data and summarize the results. Discrete variables are presented using frequency distributions and cross-tabulations. Continuous variables are summarized by presenting the number of observations, median, and range of minimum and maximum values. For correlation of normally distributed variables, the Pearson Product Moment Correlation was used; otherwise, the nonparametric Spearman rank order correlation was used. To indicate the strength and direction of the linear relationship between anterior/posterior circulation aneurysms and transient morbidity, as well as the final occlusion rate, and between aneurysm size and mortality and final occlusion rate, we performed linear regression analysis. For inferential statistics, data were analyzed by either the Student $t$ test, Fisher exact test, Mann-Whitney rank sum test, or Kruskal-Wallis 1-way analysis of variance on ranks (if not normally distributed, the Shapiro-Wilk test). For pair-wise multiple comparison procedures, the Dunn method was used. All comparisons of variables were performed at a significance level of .05 or $.01(\alpha)$ and a power of $0.80(\beta)$.

\section{RESULTS}

\section{Baseline Patient and Aneurysm Characteristics}

A total of 531 patients with 579 aneurysms were enrolled. The median age was 54 years (range, $13-86$ years), and $384(72.3 \%)$ patients were female. In $46.9 \%$ of patients, the aneurysm was an incidental finding. Headache was the presenting symptom in $18.4 \%$ of patients, and $7 \%$ had a cranial nerve palsy. In $10.9 \%$, recanalization of a previously treated aneurysm was the indication for treatment. In $3.8 \%$ of patients, a stroke was the reason for diagnosis, while subarachnoid hemorrhage occurred in $12.2 \%$; $7.7 \%$ were treated in the acute phase with subarachnoid hemorrhage. Multiple aneurysms were reported in $26.6 \%$ of patients (median number of aneurysms per patient, 1; range, 1-5). Not all those aneurysms were treated with the FRED. The median aneu-
Table 1: Baseline characteristics

\begin{tabular}{|c|c|}
\hline Characteristics & \\
\hline No. of aneurysms & 579 \\
\hline No. of patients & 531 \\
\hline No. of procedures & 534 \\
\hline \multicolumn{2}{|l|}{ Patient demographics } \\
\hline Male (No.) & $147(27.7 \%)$ \\
\hline Female (No.) & $384(72.3 \%)$ \\
\hline Age at time of treatment (median) (range) (yr) & $54(13-86)$ \\
\hline \multicolumn{2}{|l|}{ Presentation of patients (No.) } \\
\hline Incidental & $249(46.9 \%)$ \\
\hline Headaches & $98(18.4 \%)$ \\
\hline Cranial nerve palsy & $37(7 \%)$ \\
\hline Recanalization of previously treated aneurysm & $58(10.9 \%)$ \\
\hline Subarachnoid hemorrhage & $65(12.2 \%)$ \\
\hline Acute ( $\leq 3$ days) & $41(7.7 \%)$ \\
\hline Stroke & $20(3.8 \%)$ \\
\hline Other & $4(0.8 \%)$ \\
\hline Patients with multiple aneurysms (No.) & $141(26.6 \%)$ \\
\hline Aneurysms per patient (median) (range) & $1(1-5)$ \\
\hline Patients with a single aneurysm & $390(73.5 \%)$ \\
\hline Patients with 2 aneurysms & $101(19 \%)$ \\
\hline Patients with 3 aneurysms & $30(5.7 \%)$ \\
\hline Patients with 4 aneurysms & $8(1.5 \%)$ \\
\hline Patients with 5 aneurysms & $2(0.3 \%)$ \\
\hline \multicolumn{2}{|l|}{ Pretreatment mRS (per patient) (No.) } \\
\hline $0-2$ & $525(98.8 \%)$ \\
\hline $3-5$ & $6(1.2 \%)$ \\
\hline \multicolumn{2}{|l|}{ Aneurysm characteristics (No.) } \\
\hline Left & $272(47.0 \%)$ \\
\hline Right & $257(44.4 \%)$ \\
\hline Midline & $50(8.6 \%)$ \\
\hline \multicolumn{2}{|l|}{ Anterior circulation (No.) } \\
\hline \multicolumn{2}{|l|}{ Internal carotid artery } \\
\hline Posterior communicating & $50(8.6 \%)$ \\
\hline Paraophthalmic & $270(46.6 \%)$ \\
\hline Cavernous & $45(7.8 \%)$ \\
\hline Other & $67(11.5 \%)$ \\
\hline Middle cerebral artery & $37(6.4 \%)$ \\
\hline Anterior cerebral artery & $16(2.7 \%)$ \\
\hline Anterior communicating artery & $4(0.9 \%)$ \\
\hline Pericallosal artery & $13(2.2 \%)$ \\
\hline Posterior circulation (No.) & $36(6.2 \%)$ \\
\hline Basilar artery & $30(5.2 \%)$ \\
\hline Posterior cerebral artery & $9(1.6 \%)$ \\
\hline Superior cerebellar artery & $2(0.3 \%)$ \\
\hline \multicolumn{2}{|l|}{ Aneurysm morphology (No.) } \\
\hline \multicolumn{2}{|l|}{ Saccular } \\
\hline Sidewall & $459(79.2 \%)$ \\
\hline Bifurcation & $63(10.9 \%)$ \\
\hline \multicolumn{2}{|l|}{ Fusiform/dissecting/blister } \\
\hline Fusiform & $27(4.7 \%)$ \\
\hline Dissecting & $20(3.5 \%)$ \\
\hline Blister & $10(1.7 \%)$ \\
\hline Maximal diameter (median) (range) (mm) & $7.6(1-36.6)$ \\
\hline Neck diameter (median) (range) (mm) & $4.5(1-30)$ \\
\hline
\end{tabular}

rysm size was $7.6 \mathrm{~mm}$ (range, $1-36.6 \mathrm{~mm})$. Small ( $<10 \mathrm{~mm}$ ), large $(10-20 \mathrm{~mm})$, and giant $(>20 \mathrm{~mm})$ aneurysms were encountered in $76.9 \%, 17.4 \%$, and $5.7 \%$, respectively. The median aneurysm neck diameter was $4.5 \mathrm{~mm}$ (range, $1-30 \mathrm{~mm}$ ). The median dometo-neck ratio was 1.4 . In $3.8 \%$ of aneurysms, partial thrombosis was seen. Aneurysm morphology showed sidewall and bifurcation aneurysms in $79.2 \%$ and $10.9 \%$, respectively. In terms of aneurysm location, $86.7 \%$ were in the anterior circulation, with most in the internal carotid artery (Table 1). 
Table 2: Complications and adverse events per procedure

\begin{tabular}{|c|c|c|}
\hline & $\begin{array}{l}\text { Periprocedural } \\
\text { (In-Hospital } \\
\text { Stay) (No.) }\end{array}$ & $\begin{array}{c}\text { During Follow-Up } \\
\text { (after Hospital } \\
\text { Discharge) (No.) }\end{array}$ \\
\hline \multicolumn{3}{|l|}{ Complications } \\
\hline $\begin{array}{l}\text { Spontaneous rupture of the FRED-treated } \\
\text { aneurysm }\end{array}$ & 0 & 2 \\
\hline $\begin{array}{l}\text { Spontaneous nonaneurysmal intracranial } \\
\text { hemorrhage }\end{array}$ & 3 & 1 \\
\hline \multicolumn{3}{|l|}{ Symptomatic ischemic stroke } \\
\hline Minor ( $\leq 1 \mathrm{mo})$ & 8 & 5 \\
\hline Major (>1 mo) & 2 & 1 \\
\hline Stent/parent artery stenosis & 5 & 3 \\
\hline Stent/parent artery occlusion & 4 & 8 \\
\hline Permanent cranial neuropathy & 0 & 0 \\
\hline \multicolumn{3}{|l|}{ Other complications } \\
\hline Groin hematoma & 1 & \\
\hline Dissection & 1 & \\
\hline Aneurysm growth & & 2 \\
\hline Total & $24(4.5 \%)$ & $22(4.1 \%)$ \\
\hline \multicolumn{3}{|l|}{ Adverse events } \\
\hline Detachment in the hub of the microcatheter & 2 & \\
\hline Poor opening on deployment & 10 & \\
\hline Torquing of stent on deployment & 1 & \\
\hline Multiple repositioning & 2 & \\
\hline Visible gap between inner and outer stent & & 1 \\
\hline Fish mouthing of the distal stent end & & 13 \\
\hline Total & $15(2.8 \%)$ & $14(2.6 \%)$ \\
\hline Transient morbidity ( $\leq 90$ days) & $10(1.9 \%)$ & $7(1.3 \%)$ \\
\hline Permanent morbidity ( $>90$ days) & $3(0.6 \%)$ & $1(0.2 \%)$ \\
\hline Mortality & $4(0.75 \%)$ & $4(0.75 \%)$ \\
\hline
\end{tabular}

sion and a major infarct with hemorrhagic transformation. This patient died. There were 2 other nonaneurysmal hemorrhages reported from wire perforations during stent delivery, one without neurologic deterioration and one resulting in a slight transient monoparesis of the arm. Eight patients had a minor stroke postoperatively, but symptoms resolved within 1 month. During follow-up, 1 growing aneurysm resulted in a rupture 233 days after the procedure and death of the patient, and another patient died due to unexpected aneurysm rupture 1 week after the confirmation of aneurysm occlusion at 1 month. There were 3 reports of in-stent stenosis (all $<50 \%$ ) on follow-up. None of the cases of in-stent stenosis were symptomatic and needed treatment. In 12 procedures, complete occlusion of the stent, parent artery, and aneurysm complex was registered periprocedurally and during follow-up. Ten of those were asymptomatic. One patient treated for an internal carotid artery communicating segment aneurysm showed a minor infarct on MR imaging. Only 1 stent occlusion

\section{Treatment Characteristics}

Platelet-function testing was performed in $62.7 \%$ of procedures. A combination of aspirin and clopidogrel was the most common dual-antiplatelet regimen $(92.1 \%)$. The duration of dual-antiplatelet therapy varied among centers from 1 month to 1 year. A total 579 aneurysms in 531 patients were treated in 534 procedures using a median of 1 FRED (range, 1-5). In 515 procedures (96.4\%), a single FRED was used. In 5 procedures, the initial stent shortened more than expected and a second stent was placed. In 10 procedures, a second stent was intentionally used because longer stent sizes were not available at the time of the procedure. In 2 procedures, fusiform aneurysms needed 3 and 5 telescoping stents, respectively. Two procedures were for retreatment. Stent deployment was successful on first attempt in $98.3 \%$ of single FRED procedures. In $17.6 \%$ of aneurysms, concomitant aneurysm coiling was performed. In $15(2.8 \%)$ procedures, balloon angioplasty was performed, 5 of those being intentional in the absence of poor opening. The procedure time was defined from groin puncture to last angiogram and was recorded at a median of 65 minutes (range, 12-536 minutes) (On-line Table).

\section{Adverse Events and Complications}

A total of 75 (14\%) complications and adverse events were recorded. Of those, 39 (7.3\%) adverse events and complications were reported in the periprocedural and $36(6.7 \%)$ in the follow-up period. There were 3 nonaneurysmal intracranial hemorrhages. One major hemorrhage on the ipsilateral side of the treated aneurysm was detected on CT the day of the procedure after sudden neurologic deterioration. Digital subtraction angiography and MR imaging showed stent and parent artery occlu- caused the death of a patient. After routine follow-up at 6 months, a paraophthalmic aneurysm and parent artery showed complete occlusion and the antiplatelet medication was stopped. One month later the patient died from a severe stroke caused by stent occlusion.

Two aneurysms showed enlargement with time. The regrowth of a basilar trunk aneurysm caused brain stem compression. The aneurysm was retreated 2 months later with a Pipeline Embolization Device (Covidien, Irvine, California). The other aneurysm, a fusiform M1 aneurysm treated with 2 telescopic stents, was unchanged in terms of flow and showed slight growth after 9 months. At that time, a decision against retreatment was made and the antiplatelet medication was stopped. There was no change at 1-year follow-up. Clinical outcome at a median follow-up of 6.6 months was favorable. While 515 patients had a good outcome (mRS 0-2), 8 patients had a poor outcome (mRS 3-5) and another 8 patients died (mRS 6 ). In univariable analysis, posterior circulation location was associated with transient morbidity $(P<$ $.001)$, and aneurysms of $>20 \mathrm{~mm}$ were associated with mortality $(P=.047)$. In multivariable analysis, posterior circulation aneurysm was associated with transient morbidity $(\mathrm{OR}=3.661 ; 95 \%$ CI, 1.685-7.953; $P=.001$ ) (Table 2).

\section{Imaging Outcomes}

After a median follow-up time of 6.6 months (range, 0.03-45.6 months), the overall complete occlusion rate was $69.2 \%$. The number of aneurysms followed for $>3$ months was 516 (89.1\%) aneurysms. There was progressive occlusion witnessed across time, with complete occlusion in 18 (20\%) aneurysms followed 
for up to $90 \pm 14$ days, $141(82.5 \%)$ for $180 \pm 20$ days, 116 $(91.3 \%)$ for 1 year \pm 24 days, and $122(95.3 \%)$ aneurysms followed for $>1$ year. The overall aneurysm retreatment rate (using the FRED or alternative techniques and devices) was $1.2 \%$. In univariable analysis, aneurysms of $>20 \mathrm{~mm}$ were associated with incomplete occlusion using the O'Kelly-Marotta grading scale. No significant predictors of aneurysm occlusion were identified in multivariable analysis.

\section{DISCUSSION}

The EuFRED is the largest study to date to evaluate the safety and efficacy of the dual-layer flow-diverting stent, FRED. Fifteen European neurovascular centers contributed 531 patients with 579 aneurysms treated in 534 procedures during 3 years. Any aneurysm deemed suitable for FRED by the treating neurointerventionalist was eligible. The study included a wide variety of aneurysms as encountered in the real-world patient population. Transient and permanent morbidity occurred in $3.2 \%$ and $0.8 \%$, respectively, of procedures. The overall mortality rate was $1.5 \%$. Complete occlusion was achieved in $95.3 \%$ of aneurysms followed for $>1$ year.

\section{Aneurysm Characteristics in EuFRED}

Flow diversion has clearly revolutionized the endovascular treatment of aneurysms. The 2 main principles on which the concept was founded are diversion of blood flow away from the aneurysm inducing stasis and thrombosis within the aneurysm sac and endothelialization along the stent scaffold and restoration of the integrity of the arterial wall. ${ }^{8}$ These devices have effectively addressed the issue of recanalization and the need for retreatment associated with other endovascular treatment modalities and are continuously gaining popularity among neurointerventionalists. ${ }^{9}$ Whereas treatment of internal carotid artery aneurysms up to the superior hypophyseal segment provided an early experience with flow diverters, ${ }^{1}$ use has since expanded to a number of different aneurysm locations. In the EuFRED, $12.2 \%$ of aneurysms treated were in the anterior circulation distal to the internal carotid artery, and $13.3 \%$, in the posterior circulation. Thus, more than one-quarter of aneurysms were located outside traditional locations, which mirrors a trend in the literature on flow diversion that advocates its use further distal in the cerebrovascular tree at or beyond the circle of Willis. ${ }^{10-12}$ While approximately onequarter of aneurysms in the EuFRED were large and giant and deemed too difficult to treat using traditional endovascular techniques, the median aneurysm diameter of $7.6 \mathrm{~mm}$ is a testament that flow diversion may be suitable for aneurysms traditionally managed with coil embolization with or without assist devices such as stents or balloons. ${ }^{13}$

Along those lines are also the results of a matched analysis comparing flow diversion with coiling of small and uncomplicated aneurysms, demonstrating a potential benefit for the flow diverter even in simple lesions. ${ }^{14}$ The 41 (7.7\%) aneurysms in the EuFRED treated in acute aneurysmal subarachnoid hemorrhage constitute another important aspect. Nevertheless, the potential risk of rerupture due to a delay in aneurysm occlusion and the need for dual-antiplatelet agents in an acute hemorrhage remain challenges for this indication. ${ }^{15}$ There were 63 bifurcation aneurysms treated in 62 patients with a median maximal diameter of 7 $\mathrm{mm}$. Two of those aneurysms were treated in the acute phase of subarachnoid hemorrhage. Likewise, 10 blister aneurysms were treated in the setting of subarachnoid hemorrhage, 8 in the acute phase and 1 each at 1 week and 1 month. In cases of blister aneurysms treated in the acute phase, the patients were loaded with tirofiban and later transitioned to aspirin and clopidogrel.

\section{Aneurysm Occlusion after FRED}

The overall rate of complete aneurysm obliteration in EuFRED was $69.2 \%$, with a progressive increase in the proportion of aneurysms occluded with the duration of follow-up. Of aneurysms followed for $>1$ year, $95.3 \%$ were completely occluded. This observation is in line with prior studies that showed progressive aneurysm obliteration after flow diversion. In the Pipeline for Uncoilable or Failed Aneurysms (PUFS) trial, the rate of completely occluded aneurysms at 1 year was $86.8 \%{ }^{1}$ and climbed to 93.4\% at 3 years and $95.2 \%$ at 5 years. ${ }^{16,17}$ Aneurysms in PUFS, however, were notably larger at a median aneurysm diameter of $17.5 \mathrm{~mm}$ compared with $7.6 \mathrm{~mm}$ in the EuFRED. Aneurysms of $>20 \mathrm{~mm}$ were also associated with a lower rate of occlusion in the EuFRED. The notion that aneurysm size is an important predictor of aneurysm occlusion is also supported by a large multicenter retrospective study of 380 aneurysms treated with Pipeline embolization. ${ }^{18}$ In that study, the median aneurysm diameter was 7.7 $\mathrm{mm}$, comparable with that in EuFRED, and the complete occlusion rate in aneurysms followed for at least 1 year was $83.9 \%$. The study also included $13.4 \%$ of aneurysms located in the posterior circulation. Both this study and EuFRED found that posterior circulation aneurysms were less likely to occlude compared with their anterior circulation counterparts on univariable analysis. The studies were also comparable regarding the number of flow diverters used. While multiple devices were used in $98.1 \%$ of cases in PUFS, ${ }^{17}$ most aneurysms in the EuFRED and the aforementioned multicenter study were treated with a single device.

Another study to serve as a reference is the prospective Aneurysm Study of Pipeline in an Observational Registry (ASPIRe). ${ }^{19}$ Most aneurysms were also treated with a single device, but aneurysms in ASPIRe were larger than in EuFRED at a median diameter of $12 \mathrm{~mm}$. Complete occlusion rates at 6 months and 1 year were $78.6 \%$ and $78.9 \%$, respectively. ${ }^{17}$ Similar to EuFRED, size and location criteria followed country-specific instructions for use. ASPIRe also included aneurysms in the posterior circulation. ${ }^{19}$ The questions of whether occlusion rates using the FRED are indeed superior to those of other flow diverters such as Pipeline remains unanswered in the absence of a well-designed direct comparison study. Of the bifurcation aneurysms treated in EuFRED, there was progressive occlusion with time that plateaued at 1 year. Complete occlusion was noted in $38.1 \%$ at 90 days, $61.5 \%$ at 180 days, $88.8 \%$ at 1 year, and $85.7 \%$ at $>1$ year from treatment. Of the blister aneurysms, $100 \%$ were completely occluded at 3 months.

\section{Adverse Events and Complications with FRED}

In EuFRED, transient and permanent morbidity occurred in 3.2\% and $0.8 \%$ of procedures, respectively, with an overall mortality rate of $1.5 \%$. A pooled analysis of PUFS, ASPIRe, and the International Retrospective Study of the Pipeline Embolization Device, 
a retrospective study designed to assess safety-related outcomes, reported major neurologic morbidity from major ipsilateral ischemic stroke and intracranial hemorrhage in $5.7 \%$ of patients. The combined major neurologic morbidity and mortality was $7.1 \% .{ }^{17}$ A meta-analysis including 1654 Pipeline-treated aneurysms and aneurysms treated with the Silk flow diverter (Balt Extrusion, Montmorency, France) reported procedure-related morbidity and mortality rates of $5 \%$ and $4 \%$, respectively. Ischemic stroke and perforator infarction rates were significantly higher in the posterior compared with the anterior circulation. Large and giant aneurysms had higher odds of ischemic stroke and subarachnoid hemorrhage. ${ }^{20}$ Similar relationships were also detected in EuFRED, in which transient morbidity was associated with posterior circulation location and mortality with aneurysms of $>20 \mathrm{~mm}$. Of the bifurcation aneurysms treated, 1 patient had a major ipsilateral hemorrhage the day of the procedure. Digital subtraction angiography and MR imaging showed stent and parent artery occlusion resulting in a major infarct with hemorrhagic transformation and death. Except for this patient, all other patients had at least 90 days of follow-up and an mRS score between 0 and 2. Among the patients with blister aneurysms, all had an mRS score between 0 and 1 at last follow-up.

\section{Strengths and Limitations}

The main limitation of the present study is selection bias across the different neurovascular centers and individual neurovascular practitioners. No patient- and aneurysm-specific inclusion and exclusion criteria were provided, to mirror the real world. Likewise, periprocedural and follow-up management was at the discretion of the institution, reflected in variations in platelet-function testing, antiplatelet therapy, use of adjunctive coiling, and imaging follow-up schedule. While patients were prospectively enrolled, data collection was retrospective and subject to incomplete datasets. Data collection was performed at the individual institution and not at a central location, a core lab, introducing potential bias. The inclusion of multiple institutions, however, improved the generalizability of the findings. While participating practitioners were encouraged to enroll consecutive cases, it is possible that alternative flow diverters were used occasionally during the study period.

\section{CONCLUSIONS}

The EuFRED is the largest study to date assessing the safety and efficacy of the FRED flow-diverting stent. Applied to what may be considered a real-world patient population, FRED performed favorably regarding aneurysm obliteration and complications. Well-designed studies comparing FRED with other flow diverters are required to substantiate those observations.

Disclosures: Monika Killer-Oberpfalzer-UNRELATED: Grant: MicroVention/ Terumo, Comments: research grant*; Support for Travel to Meetings for the Study or Other Purposes: MicroVention/Terumo; Travel/Accommodations/Meeting Expenses Unrelated to Activities Listed: MicroVention, Stryker, Medtronic. Naci KocerUNRELATED: Consultancy: MicroVention, Medtronic, Comments: consultant and proctorship agreement; Payment for Lectures Including Service on Speakers Bureaus: MicroVention, Comments: lectures on FRED. Hendrik Janssen-UNRELATED: Consultancy: MicroVention/Sequent Medical, Comments: proctor*; Travel/Accommodations/Meeting Expenses Unrelated to Activities Listed: MicroVention, Comments: travel expenses for conferences.* Markus Holtmannspötter-UNRELATED: Consultancy: Medtronic, MicroVention, Sequent Medical, Stryker, Route 92, Comments: consultancy and proctoring agreement; Payment for Lectures Including Service on Speakers
Bureaus: Medtronic, MicroVention, Sequent Medical. Jan-Hendrik Buhk—UNRELATED: Consultancy: Acandis, Codman Neurovascular, Medtronic, MicroVention, Stryker. Johannes Trenkler-UNRELATED: Payment for Lectures Including Service on Speakers Bureaus: MicroVention, Comments: interventional workshops, on-line presentation; Travel/Accommodations/Meeting Expenses Unrelated to Activities Listed: MicroVention, Stryker, Medtronic.* Ansgar Berlis_UNRELATED: Consulting Fee or Honorarium: MicroVention (FRED, Phil, WEB), Comments: proctoring. Markus Möhlenbruch—UNRELATED: Board Membership: Codman Neurovascular; Consultancy: Medtronic*; Grants/Grants Pending: Balt, MicroVention*; Payment for Lectures Including Service on Speakers Bureaus: MicroVention, phenox, Stryker.* *Money paid to the institution.

\section{REFERENCES}

1. Becske T, Kallmes DF, Saatci I, et al. Pipeline for uncoilable or failed aneurysms: results from a multicenter clinical trial. Radiology 2013; 267:858-68 CrossRef Medline

2. Briganti F, Leone G, Cirillo L, et al. Postprocedural, midterm, and long-term results of cerebral aneurysms treated with flow-diverter devices: 7-year experience at a single center. Neurosurg Focus 2017; 42:E3 CrossRef Medline

3. Pivotal Study of the FRED Stent System in the Treatment of Intracranial Aneurysms. ClinicalTrials.gov. https://www.clinicaltrials.gov/ ct2/show/NCT01801007?term $=$ FRED\&cond $=$ Aneurysm\&rank $=1$. Accessed December 18, 2017

4. Luecking H, Engelhorn T, Lang S, et al. FRED flow diverter: a study on safety and efficacy in a consecutive group of 50 patients. AJNR Am J Neuroradiol 2017;38:596-602 CrossRef Medline

5. Möhlenbruch MA, Herweh C, Jestaedt L, et al. The FRED flow-diverter stent for intracranial aneurysms: clinical study to assess safety and efficacy. AJNR Am J Neuroradiol 2015;36:1155-61 CrossRef Medline

6. Drescher F, Weber W, Berlis A, et al. Treatment of intra- and extracranial aneurysms using the Flow-Redirection Endoluminal Device: multicenter experience and follow-up results. AJNR Am J Neuroradiol 2017;38:105-12 CrossRef Medline

7. O'Kelly CJ, Krings T, Fiorella D, et al. A novel grading scale for the angiographic assessment of intracranial aneurysms treated using flow diverting stents. Interv Neuroradiol 2010;16:133-37 CrossRef Medline

8. Griessenauer CJ, Gupta R, Shi S, et al. Collar sign in incompletely occluded aneurysms after Pipeline embolization: evaluation with angiography and optical coherence tomography. AJNR Am J Neuroradiol 2017;38:323-26 CrossRef Medline

9. Fargen KM, Soriano-Baron HE, Rushing JT, et al. A survey of intracranial aneurysm treatment practices among United States physicians. J Neurointerv Surg 2018;10:44-49 CrossRef Medline

10. Dabus G, Grossberg JA, Cawley CM, et al. Treatment of complex anterior cerebral artery aneurysms with Pipeline flow diversion: mid-term results. J Neurointerv Surg 2017;9:147-51 CrossRef Medline

11. Bhogal $P$, Martinez R, Gansladt $O$, et al. Management of unruptured saccular aneurysms of the M1 segment with flow diversion: a single centre experience. Clin Neuroradiol 2016 Dec 11. [Epub ahead of print] CrossRef Medline

12. Lopes DK, Jang DK, Cekirge S, et al. Morbidity and mortality in patients with posterior circulation aneurysms treated with the Pipeline embolization device: a subgroup analysis of the international retrospective study of the Pipeline embolization device. $\mathrm{Neu}$ rosurgery 2017 Sep 18. [Epub ahead of print] CrossRef Medline

13. Brinjikji W, Cloft HJ, Kallmes DF. Difficult aneurysms for endovascular treatment: overwide or undertall? AJNR Am J Neuroradiol 2009;30:1513-17 CrossRef Medline

14. Chalouhi N, Daou B, Barros G, et al. Matched comparison of flow diversion and coiling in small, noncomplex intracranial aneurysms. Neurosurgery 2017;81:92-97 CrossRef Medline

15. Walcott BP, Koch MJ, Stapleton CJ, et al. Blood flow diversion as a primary treatment method for ruptured brain aneurysms: concerns, controversy, and future directions. Neurocrit Care 2017;26: 465-73 CrossRef Medline

16. Becske T, Potts MB, Shapiro M, et al. Pipeline for uncoilable or failed 
aneurysms: 3-year follow-up results. J Neurosurg 2017;127:81-88 CrossRef Medline

17. Kallmes DF, Brinjikji W, Cekirge S, et al. Safety and efficacy of the Pipeline embolization device for treatment of intracranial aneurysms: a pooled analysis of 3 large studies. J Neurosurg 2017; 127:775-80 CrossRef Medline

18. Adeeb N, Moore JM, Wirtz M, et al. Predictors of incomplete occlusion following Pipeline embolization of intracranial aneurysms: is it less effective in older patients? AJNR Am J Neuroradiol 2017;38: 2295-2300 CrossRef Medline

19. Kallmes DF, Brinjikji W, Boccardi E, et al. Aneurysm Study of Pipeline in an Observational Registry (ASPIRe). Interv Neurol 2016;5: 89-99 CrossRef Medline

20. Brinjikji W, Murad MH, Lanzino G, et al. Endovascular treatment of intracranial aneurysms with flow diverters: a meta-analysis. Stroke 2013;44:442-47 CrossRef Medline 